\title{
IL-17-producing peripheral blood CD177 neutrophils increase in allergic asthmatic subjects
}

\author{
Carlos Ramirez-Velazquez ${ }^{1,2}$, Elena Cristina Castillo ${ }^{1}$, Leopoldo Guido-Bayardo ${ }^{3}$ and Vianney Ortiz-Navarrete ${ }^{1 *}$
}

\begin{abstract}
Background: A T helper cell $\left(T_{H}\right)$ 17-biased response has been observed in patients with allergic asthma, particularly in those with neutrophil accumulation in the lung. Therefore, we sought to test the hypothesis that neutrophils might be an important source of interleukin (IL)-17 in allergic asthma.

Methods: Whole peripheral blood cells from non-asthmatic control subjects $(n=17)$ and patients with mild asthma $(n=7)$, moderate but persistent asthma $(n=4)$, or acute asthma $(n=6)$ were analyzed for IL-17A expression in $\mathrm{CD} 177^{+}$neutrophils. IL-17A expression was also analyzed in $\mathrm{CD}^{+} \mathrm{CD}^{+}$and $\mathrm{CD}^{+} \mathrm{CD}^{+}$lymphocyte populations. Asthmatic patients were classified as allergic to fungi, indoor allergens, or other allergens (e.g., pollen) based on a positive intradermal allergy test reaction.
\end{abstract}

Results: The percentage of $\mathrm{CD} 177^{+}$neutrophils in whole blood of asthmatic patients was higher than in healthy controls and highest in the moderate asthma group. Furthermore, the percentage of $\mathrm{CD} 177^{+} \mathrm{IL}-17^{+}$neutrophils was elevated in patients with mild asthma, whereas the $\mathrm{CD} 4^{+} \mathrm{IL}-17^{+}$lymphocyte population was higher in asthmatic patients and highest in those with moderate but persistent asthma. We also found that the four patients that were allergic to fungi had the highest percentage of $\mathrm{CD} 177^{+} \mathrm{IL} 17^{+}$neutrophils and $\mathrm{CD} 8^{+} \mathrm{IL} 17^{+}$lymphocytes.

Conclusion: $\mathrm{IL} 17^{+} \mathrm{CD} 177^{+}$Neutrophils increase in allergic asthma patients especially when allergic to fungi. This cell population, through release of IL-17, might be contributing during the initial phase asthmatic disease and/or during disease progression but its role has not yet been established.

Keywords: Neutrophils, IL-17, Allergic asthma, Blood

\section{Background}

Asthma is a heterogeneous chronic inflammatory respiratory disease characterized by overproduction of mucus and airway-wall remodeling that leads to bronchial hyperactivity and airway obstruction [1]. Allergens and some pathogens have been implicated in the worsening of asthma [2,3], and the disease can be classified as mild, moderate, or severe according to the magnitude of the inflammation [4].

For many years, allergic asthma has been considered a $\mathrm{T}$ helper $2\left(\mathrm{~T}_{\mathrm{H}} 2\right)$-biased disease, characterized by eosinophil infiltration and the production of the cytokines interleukin (IL)-4, IL-5, and IL-13 [5]. A $\mathrm{T}_{\mathrm{H}}$ 17-biased response has also been observed in patients that exhibit

\footnotetext{
*Correspondence: vortiz@cinvestav.mx

${ }^{1}$ Molecular Biomedicine Department, Centro de Investigación y de Estudios Avanzados (CINVESTAV)-IPN, Av. IPN No. 2508, Colonia San Pedro Zacatenco, México, DF CP. 07360, México

Full list of author information is available at the end of the article
}

chronic inflammation [6] and particularly in those with severe asthma who respond poorly to steroids, where inflammatory cellular infiltration in the airway is primarily due to $\mathrm{CD} 4^{+} \mathrm{T}_{\mathrm{H}} 17$ cells and neutrophils [7-9].

Neutrophils have been associated with the severity of asthma $[10,11]$. Moreover, studies in humans have demonstrated neutrophil recruitment in response to allergen challenge that coincides with the peak of $\mathrm{CD} 4^{+} \mathrm{T}$-cell recruitment. The peak of eosinophil recruitment occurs several days later [12], suggesting the importance of neutrophils in the pathogenesis of the disease. In addition, it has been reported that IL-17 favors neutrophil recruitment and leads to the induction of neutrophilia rather than eosinophilia in rodents $[13,14]$. The numbers of neutrophils in the sputum $[9,10,15]$, bronchoalveolar lavage [12], bronchial biopsies [16,17], and peripheral blood [18] of allergic asthmatic patients have been shown to increase concomitantly with IL-17 levels [7,19-21].

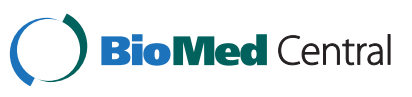


IL-17 is mainly produced by $\mathrm{T}_{\mathrm{H}} 17$ cells, but also by $\mathrm{CD}^{+} \mathrm{T}$ cells, $\gamma \delta \mathrm{T}$ cells, natural killer cells, and granulocytes [22]. In addition, it has been shown that murine neutrophils release IL-17 [13,23], but no further studies have investigated the expression and release of IL-17A -the most common form of IL-17- from human peripheral blood neutrophils in neither a normal state or during disease ( e.g., allergic asthma).

In this study, we demonstrated that in fact human neutrophils are able to express IL-17. We also observed increased numbers of IL-17A + neutrophils in peripheral blood of asthmatic patients particularly in those suffering from fungal allergy-associated asthma.

\section{Methods}

\section{Patients and control subjects}

We recruited 17 asthmatic patients and all of them tested positive in the allergen skin prick test (Alerquim, Mexico City) to at least one of following: house dust mites, pollens, and fungi. We classified the asthma severity in our patients according to Global strategy for asthma management and prevention: GINA executive summary 2008 [24]. In our study we only included patients who matched the mild (seven patients) or moderate (four patients) categories according to GINA.

We also included acute asthma patients (six patients) defined as those who show exacerbation in symptoms such as wheezing, breathlessness, and chest tightness 48 hours prior to admission to the emergency department and received only rescue medication. These patients were enrolled within 24 hours of admission to the emergency department. Prior to the start of treatment, a blood sample was obtained for this study. However, three out of the six patients with acute asthma had inhaled 32 -agonist short acting bronchodilators $48 \mathrm{~h}$ before their hospital admission. Patients who had an infection process along with the exacerbation were not included.

All subjects (asthmatic and control) were either nonsmokers or former smokers who had quit smoking for at least 12 months. Subjects who had used corticosteroids, long-acting $\beta 2$-agonists, leukotriene antagonists, or antihistamines in the month preceding the study were excluded, so were subjects with history of respiratory tract infection in the 4 weeks preceding the study. Healthy subjects without history of allergy or bronchial symptoms and who tested negative in the allergen skin prick test (Alerquim) made up the control group. Total serum immunoglobulin E was measured in every subject as well as the forced expiratory volume in 1 second (FEV1). Table 1. Three different independent measurements of FEV1 were performed with a dry spirometer (Medgraphics, Minnesota, USA) and the optimum value was expressed as a percentage of the predicted value. The Ethics Committee of the Fernando Quiroz Hospital approved the study, and each subject gave written informed consent.

\section{Preparation of human mononuclear cells}

Whole blood cells were obtained from 17 healthy volunteers and 17 asthmatic patients. Peripheral blood mononuclear cells (PBMCs) were isolated using a differential centrifugation gradient (Ficoll-Paque PLUS, GE Healthcare). The PBMCs were analyzed for viability with trypan blue, washed, and grouped into two, either for the ex-vivo staining or in vitro activation.

\section{Cell activation}

Heparinized whole blood (HWB; $500 \mu \mathrm{L}$ ) was stimulated with $2 \mu \mathrm{g} / \mathrm{mL}$ ionomycin (Sigma-Aldrich) and $40 \mathrm{ng} / \mathrm{mL}$ phorbol myristate acetate (PMA; Sigma-Aldrich) for $18 \mathrm{~h}$ at $37^{\circ} \mathrm{C}$. PBMCs were stimulated with $200 \mathrm{ng} / \mathrm{mL}$ ionomycin and $2 \mathrm{ng} / \mathrm{mL}$ PMA for 18 hours at $37^{\circ} \mathrm{C}$. In both cases $10 \mu \mathrm{g} / \mathrm{mL}$ brefeldin A (BFA; Sigma-Aldrich) was added during the last 6 hours of culture activation.

\section{Surface staining and intracellular cytokine detection}

Cells from activated and non-activated HWB were stained with fluorescein isothiocyanate (FITC)-conjugated anti-CD177 and phycoerythrin (PE)-conjugated anti-IL-5R $\alpha(R \& D)$ for $20 \mathrm{~min}$ at $4^{\circ} \mathrm{C}$. Blood erythrocytes were lysed with lysis buffer solution (155 mM NH4C1, $10 \mathrm{mM}$ KHCO3, and 0.1 mM EDTA, pH 7.3) for $15 \mathrm{~min}$ at room temperature (RT). Subsequently, cells were permeabilized using FACS Perm2 solution (BD Biosciences, San Jose, CA, USA) for $10 \mathrm{~min}$ based on manufacturer recommendations. Then samples were stained with peridinin chlorophyll-A protein (PerCP)/Cy5.5 conjugated anti-IL-17A (BioLegend). Finally cells were fixed with $2 \%$ paraformaldehyde (PFA) and analyzed using a CyAn ADP cytometer (Beckman Coulter, Inc. Indianapolis, IN; USA). Activated and non-activated PBMCs were stained with FITC-conjugated anti-CD-3, allophycocyanin

\section{Table 1 Characteristics of study subjects}

\begin{tabular}{lcc}
\hline & Asthmatics & $\begin{array}{c}\text { Non-asthmatic } \\
\text { controls }\end{array}$ \\
\hline Sex (female/male) & $6 / 11$ & $7 / 10$ \\
Age (y) (mean \pm SEM) & $22.35 \pm 3.82$ & $24.12 \pm 1.38$ \\
Atopy (No) ${ }^{1}$ & $17 / 17$ & $0 / 17$ \\
Serum total lgE levels (IU/mL) & $425.2 \pm$ & $278.89 \pm 14.6$ \\
(mean \pm SEM) $^{*}$ & $105.2^{* *}$ & \\
FEV1 (\% predicted) & $48-117$ & $88-111$ \\
(mean \pm SEM) & $(77.65 \% \pm$ & $(96.59 \% \pm 1.61)$ \\
& $4.77)^{* *}$ & \\
\hline
\end{tabular}

${ }^{1}$ Atopy is defined as at least one positive prick test.

${ }^{* *} P<.01$ compared to non-asthmatic controls.

Abbreviations: FEV1 Forced expiratory volume in 1 second, $1 \mathrm{~g}$ Immunoglobulin, SEM Standard error of the mean. 
(APC)-Cy7-conjugated anti-CD4 and PE-conjugated antiCD8 for $20 \mathrm{~min}$ at $4^{\circ} \mathrm{C}$ and afterwards permeabilized, stained for IL-17A and CD69, and fixed as described above. Cells were washed after fixation and analyzed with a CyAn ADP cytometer (Beckman Coulter). Isotypecontrol matched mAbs (BioLegend) were used as negative controls for each fluorochrome.

\section{Flow cytometry analysis}

Neutrophils were identified according to size (forward scatter, FSC) and complexity (side scatter, SSC) and by the expression of CD177 (BioLegend). Eosinophils IL$5 \mathrm{R} \alpha$ marker was used to distinguish them from neutrophils in HWB to further determine the percentage of CD $177^{+} \mathrm{IL}^{+} 7^{+}$neutrophils. IL-17 expression was also evaluated in $\mathrm{CD}^{+} \mathrm{CD}^{+}$and $\mathrm{CD}^{+} \mathrm{CD}^{+}$lymphocytes from PBMCs previously gated according to FSC and SSC as well. CD69 was used as an activation marker for $T$ cells which were activated with ionomycin-PMA. Data analysis was performed using the FlowJo 5.6.4. software.

\section{Statistical analysis}

Distributions of continuous variables are expressed as mean \pm standard error (SEM) and median. A nonparametric Mann-Whitney $U$ test was used to compare continuous variables, the Wilcoxon test for 2-group comparisons, and the Kruskal-Wallis test for multiple comparisons. The Friedman post hoc test was used to confirm differences in individual groups. $P$ values less than .05 were interpreted to indicate significance.

\section{Results}

Peripheral blood neutrophils express IL-17 and increase in number in allergic asthma patients

The neutrophils population in HWB was analyzed by flow cytometry according to size (forward scatter, FSC) and complexity (side scatter, SSC) as well as the expression of CD177 (Figure 1). The percentage of neutrophils in the whole blood of asthmatic patients was higher than in healthy controls $(P=.012$; Figure $2 \mathrm{~A})$, and was highest in patients with moderate asthma $(P=.0001)$, but no differences were observed between patients with acute
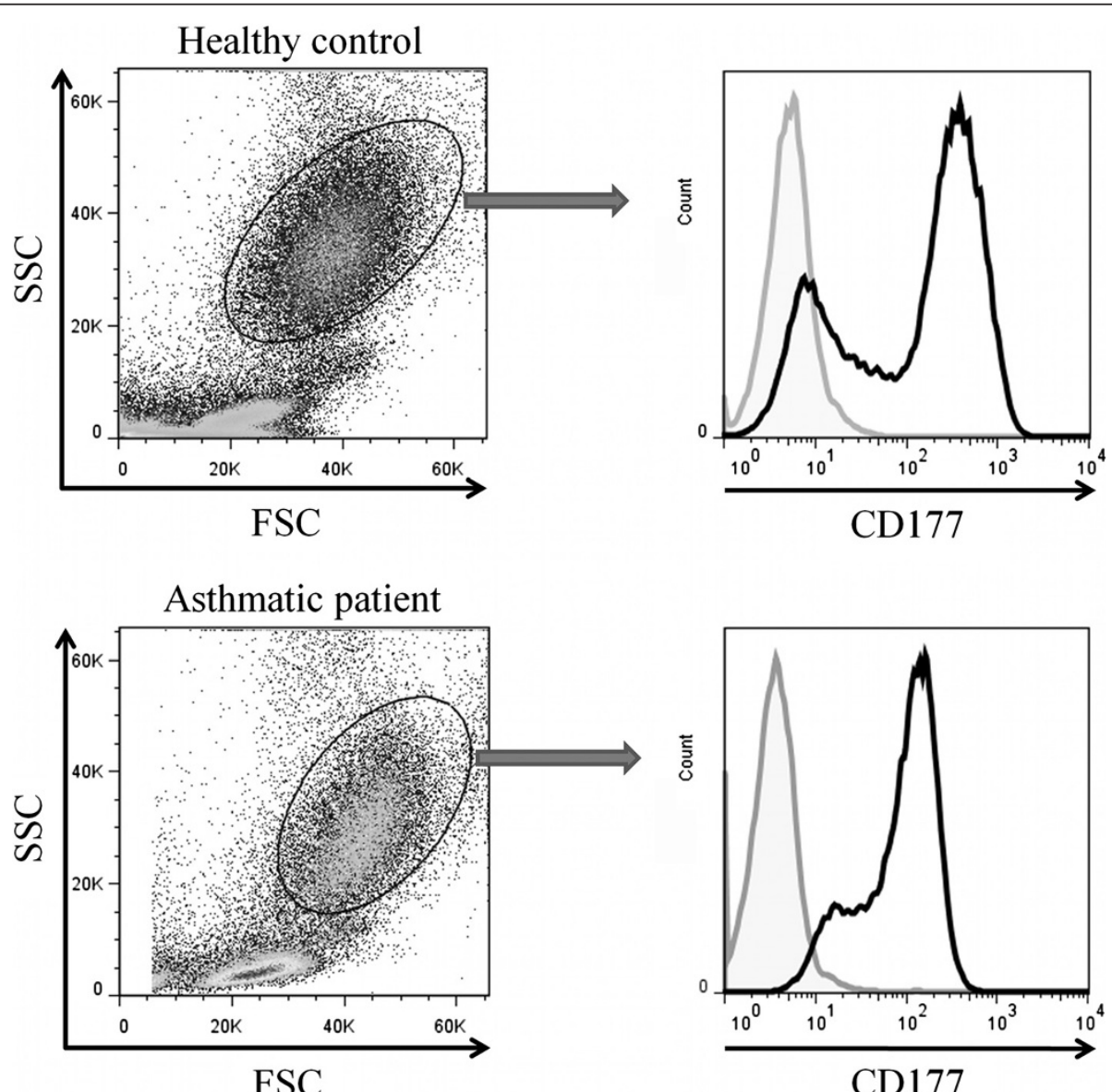

Figure 1 Peripheral blood neutrophils were identified within the granulocytes cells according to size (forward scatter), complexity (side scatter) and CD177 expression. A representative dot plot and histogram is shown from one patient and one healthy control. 
asthma and healthy controls (Figure 2B). We observed that the percentage of $\mathrm{CD} 177^{+} \mathrm{IL}-17^{+}$neutrophils in allergic asthmatic patients was higher $(P=.003)$ when compared to healthy controls (Figure 3A, 3B). No further increase was observed when neutrophils were stimulated with ionomycin/PMA (data not shown). In addition, we found that the percentage of $\mathrm{CD} 177^{+} \mathrm{IL}-17^{+}$neutrophils increased in mild $(P=.01)$, moderate $(P=.005)$ and acute asthma $(P=.041)$ in comparison to healthy controls. The $\mathrm{CD} 177^{+} \mathrm{IL}-17^{+}$neutrophils percentage was highest in patients diagnosed with mild asthma, as compared to that in those with moderate asthma $(P=.0108)$ or acute asthma $(P=.0001)$. However, no significant difference was observed between the latter two groups (Figure 3C).

\section{The percentage of IL-17A ${ }^{+}$neutrophils in peripheral} blood is higher in asthma patients with fungal allergy

We sought to determine if a specific type of allergen preferentially activated the neutrophil response. To address this we analyzed the percentage of $\mathrm{CD} 177^{+} \mathrm{IL}-17 \mathrm{~A}^{+}$ neutrophils from asthmatic patients that are allergic to specific groups of allergens based on positive intradermal allergy test reactions. Patients were divided into two groups: asthmatic patients allergic to fungi (Penicilium, Rhizopus, Candida albicans, Alternaria alternata, and Aspergillus fumigatus) and asthmatic patients allergic to other allergens such as pollens (Lolium perenne, Fraxinus, Liquidambar, Pinus, Quercus, Olea europeae, Amaranthus palmeri, Prosopis, and Chenopodium album) and indoor allergens (dust mites, dogs, cats, and cockroaches). We found that asthmatic patients that are allergic to fungi (4 out of 17) had a higher percentage of CD177 ${ }^{+} \mathrm{IL}-17^{+}$ neutrophils in their peripheral blood compared to patients with allergic asthma that are reactive to other allergens $(P=.0001$; Table 2). Figure 3D shows that patients with mild asthma who are allergic to fungi (2 out of 6) exhibited the highest percentage of $\mathrm{CD} 177^{+} \mathrm{IL}-17^{+}$neutrophils as compared to those patients with mild asthma who are allergic to other allergens $(P=.029)$ and to healthy controls (allergic fungal $P=.0001$, other allergens
\& $P=.04)$. While analyzing the numbers of neutrophils, we observed an increase in both the percentage of cells that express IL-17 and the number of neutrophils $(P=.006$; Table 2$)$. This data suggests a positive association between neutrophils, fungal allergens, and asthma.

In addition, we analyzed the percentage of $\mathrm{IL}-17 \mathrm{~A}^{+} \mathrm{T}$ cells stratified according to the two groups of allergens in the asthmatic patients. We found that the percentage of $\mathrm{CD}^{+} \mathrm{IL}^{-17^{+}} \mathrm{T}$ cells was higher in patients that are allergic to fungi $(P=.006$; Table 2$)$. On the other hand the percentage of $\mathrm{CD}_{4}^{+} \mathrm{IL}_{-17 \mathrm{~A}^{+}} \mathrm{T}$ cells remained unchanged $(P=.38$; Table 2$)$ even between patients allergic to pollens and indoor allergens (data not shown).

\section{$\mathrm{CD4}^{+} \mathrm{IL}-17^{+} \mathrm{T}$ lymphocytes increase in number according to asthma severity}

PBMCs were isolated from peripheral blood of allergic asthma patients and healthy controls in order to identify IL-17+ CD4 $4^{+} \mathrm{T}$ cells. Analysis was performed using flow cytometry based on the expression of molecular markers by selecting the $C D 4^{+} \mathrm{IL} 17 \mathrm{~A}^{+}$population by gating for lymphocytes. We observed that the percentage of $\mathrm{CD} 4^{+}$ IL-17A ${ }^{+} \mathrm{T}$ cells was higher in allergic asthma patients than in healthy controls $(P=.02$; Figure $4 \mathrm{~A})$. We found that the percentage of $\mathrm{CD} 4^{+} \mathrm{T}$ cells was higher in all groups (mild $P=.007$, moderate $P=.0001$, acute $P=.04$ ) the highest being in moderate asthma patients $(P=.03)$. We found no difference between patients with acute asthma and those with moderate asthma (Figure 4B).

\section{Discussion}

Multiple lines of evidence show a link between an increase in neutrophil numbers and the exacerbation, progression, severity, and difficulties in the control of asthmatic disease $[9,10,15]$, not just at the bronchial level but also in peripheral blood [18]. Some mediators of these cells such as matrix metalloproteinase-9 [25], lactoferrin [26], reactive oxygen species [27], and IL-8 [28] have been associated with poor clinical evolution of the disease. During this study, even though only a small
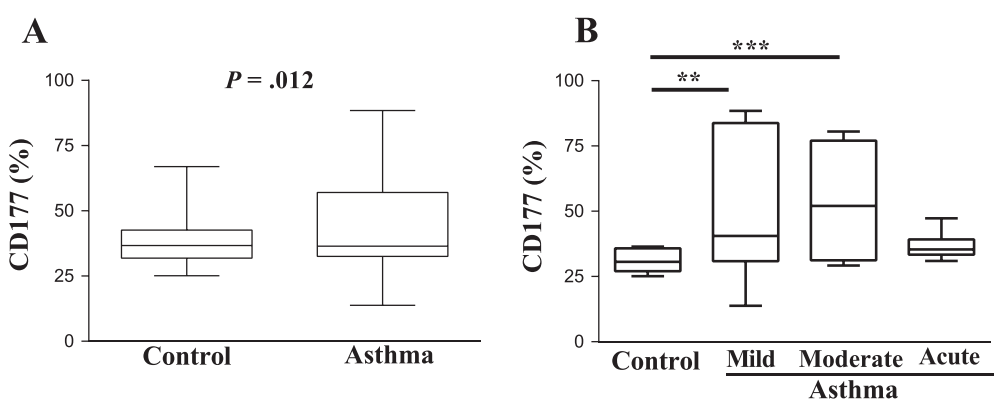

Figure 2 Neutrophils increase in patients with allergic asthma. (A) The percentage of CD177 neutrophils in allergic asthma and healthy control subjects is shown. (B) Percentages of $\mathrm{CD} 177^{+}$neutrophils from patients with mild, moderate, and acute asthma in comparison with control non-asthmatic subjects. The asterisks indicate ${ }^{* *} P=.01,{ }^{* * *} P=.0001$. Error bars indicate SEM. 
A

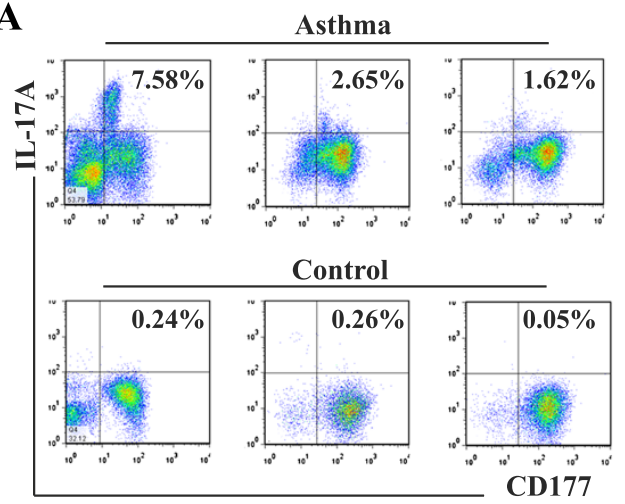

C

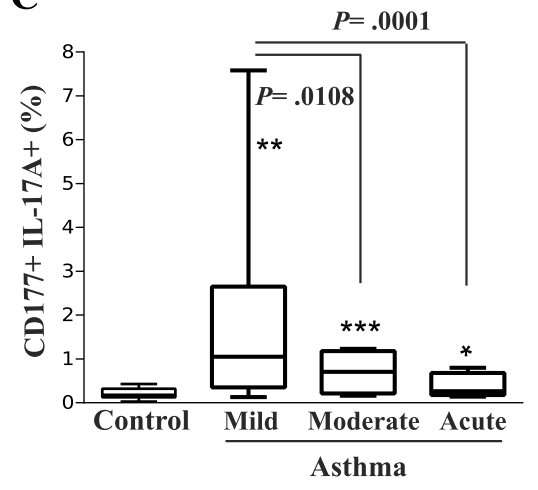

B

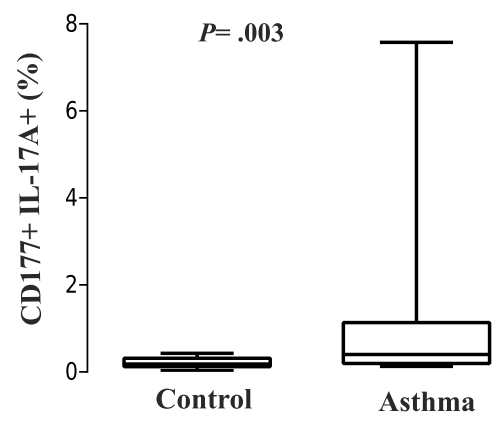

D

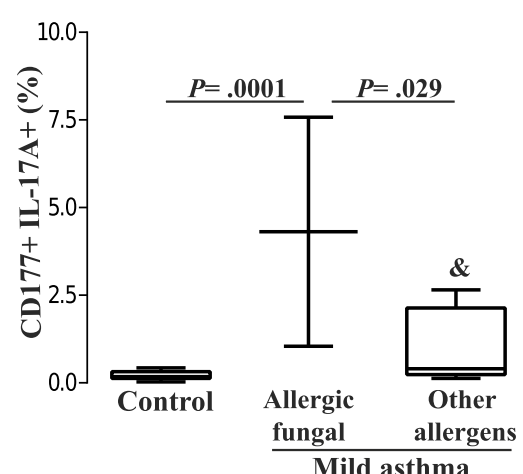

Figure 3 Neutrophils express IL-17A. (A) Percentages of $C D 177^{+} \mathrm{IL}-17 \mathrm{~A}^{+}$neutrophils from allergic asthma patients and healthy controls. (B) Percentages of $C D 177^{+}$cells that are IL-17A . (C) Percentage of IL-17A cells stratified by the severity of allergic asthma and (D) by responses to allergy tests in mild asthma patients. The symbols indicate ${ }^{*} P=.04,{ }^{*} P=.01,{ }^{*}{ }^{*} P=.005$, and $\& P=.001$. Error bars indicate SEM., and $\& P=.001$.

number of patients was analyzed, we found an increase in the percentage of neutrophils in peripheral blood from allergic asthmatic patients. In this same group of patients we observed an $\mathrm{IL}-17^{+}$neutrophil subpopulation increase. The highest increase in this subpopulation was seen in patients with mild asthma. This result suggests that $\mathrm{CD} 177^{+} \mathrm{IL}-17 \mathrm{~A}+$ neutrophils might play a role in the early stages of the response. The difference in the number of IL-17A ${ }^{+}$neutrophils in the three evaluated groups did not change even after cells were

Table 2 Comparisons of biomarkers in patients allergic to fungal allergens and to other allergens

\begin{tabular}{|c|c|c|c|}
\hline & $\begin{array}{l}\text { Fungal allergens } \\
\qquad(n=4)\end{array}$ & $\begin{array}{l}\text { Other allergens (indoor and pollen allergens) } \\
\qquad(n=13)\end{array}$ & $\begin{array}{c}P \\
\text { value* }\end{array}$ \\
\hline CD177+ IL-17A + (\%) & $2.465 \pm 1.716$ & $0.6938 \pm 0.205$ & 0.0001 \\
\hline IL-17+ TCD4+ (\%) & $0.405 \pm 0.233$ & $0.417 \pm 0.165$ & 0.3801 \\
\hline IL-17+ TCD8+ (\%) & $0.277 \pm 0.196$ & $0.148 \pm 0.042$ & 0.0065 \\
\hline Neutrophil count $\left(\mathrm{mm}^{3}\right)$ & $7325 \pm 1656$ & $3761 \pm 356.0$ & 0.0067 \\
\hline Eosinophil count $\left(\mathrm{mm}^{3}\right)$ & $390.8 \pm 218.3$ & $693.5 \pm 102.7$ & 0.2931 \\
\hline $\mathrm{CD}^{+} \mathrm{T}$ cells $\left(\mathrm{mm}^{3}\right)$ & $347.8 \pm 147.8$ & $507.9 \pm 79.41$ & 0.4001 \\
\hline $\mathrm{CD}^{+} \mathrm{T}$ cells $\left(\mathrm{mm}^{3}\right)$ & $229.9 \pm 56.56$ & $363.5 \pm 90.93$ & 0.0528 \\
\hline Serum total lgE levels (IU/mL) & $496.43 \pm 294.0$ & $352.0 \pm 81.82$ & 0.0352 \\
\hline FEV1 (\% predicted) & $83.75 \pm 14.21$ & $75.00 \pm 4.99$ & 0.1097 \\
\hline
\end{tabular}

Data are shown as mean \pm standard errors of the mean.

Abbreviations: FEV1 Forced expiratory volume in 1 second, Ig Immunoglobulin, IL Interleukin. 
A

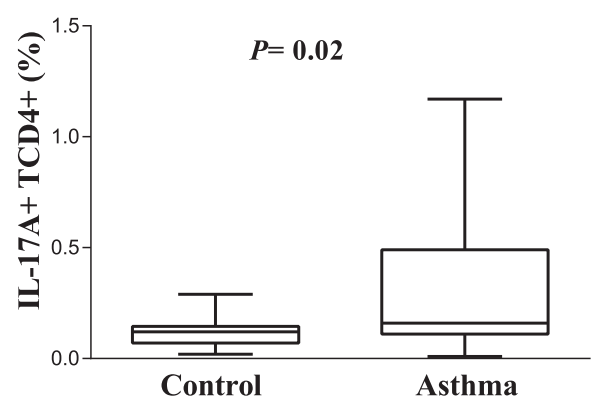

B

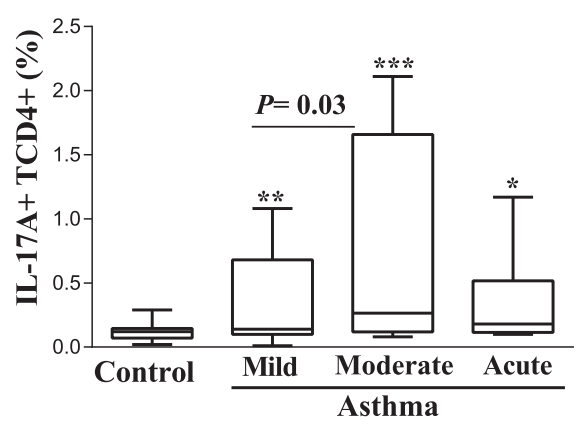

Figure 4 Percentage of $\mathrm{CD}^{+} \mathrm{T}$ cells expressing IL-17 (Th17) in asthmatic patients. (A) Comparison of the percentages of Th17 cells from patients and controls. (B) Percentage of Th17 cells stratified according to disease severity. Asterisks indicate ${ }^{*} P=.04,{ }^{* *} P=.007,{ }^{* * *} P=.0001$. Error bars indicate SEM.

stimulated in vitro with ionomycin/PMA (data not shown). This indicates the possible existence of neutrophils that have been polarized to produce IL-17A, as has been described for $\mathrm{CD}^{+} \mathrm{IL}^{-17^{+}} \mathrm{T}$ cells. However, further studies are required to evaluate whether or not these neutrophils subpopulation express the nuclear hormone receptor RORyt [22]. Recently, Tan Z et al., demonstrated that $\mathrm{Gr}-1^{\text {hi }}$ mouse neutrophils express RORyt and these cells express IL-17A mRNA after stimulation with LPS, LPS/IL-1 $\beta$, or PMA/ionomycin suggesting that these cells have the capacity to produce IL-17A. The RORyt neutrophils appear to amplify inflammation and damage in ischemia-reperfusion (I/R) injury. Taz Z et al. also showed the presence of $\mathrm{CD} 15^{\mathrm{hi}} \mathrm{IL}-17^{+}$neutrophils population in peripheral blood from seven patients who underwent partial hepatectomy. Remarkably these $\mathrm{CD} 15^{\text {hi }}$ neutrophils expressing IL-17A increased upon surgical intervention[29]. However, they are yet to prove whether these cells express RORyt. Their results resemble ours in that there is an IL-17A subpopulation of neutrophils in peripheral blood and that those cells might play a role in pathogenesis thought the release of IL-17A. However, whether this CD $15^{\text {hi }} \mathrm{IL}-17^{+}$neutrophil subpopulation is the same as the one described by us is yet to be determined.

We found that patients with fungal allergies (4 of 17) had the highest number of $\mathrm{CD} 177^{+} \mathrm{IL}-17^{+}$neutrophils. In this regard, Inoue et al. reported that the use of $\beta$-glucan from Candida albicans in the lungs of mice induces neutrophilic airway inflammation and the expression of different cytokines such as IL-17 [30]. Furthermore, Werner et al. reported that mouse neutrophils produce IL-17 in a dectin-1-dependent manner following infection with Aspergillus fumigatus [31]. Thus, we suggest that fungal allergens and their derivatives might activate neutrophils through the dectin-1 receptor, inducing IL-17 production and contributing to bronchial inflammation during allergic asthma.

Additionally, we observed that the numbers of $\mathrm{CD}^{+}$ $\mathrm{T} \mathrm{IL}-17^{+}$cells also increased in patients with fungal allergy asthma. Consistent with this observation, it has been reported that neutrophils regulate the infiltration of $\mathrm{CD}^{+} \mathrm{T}$ cells to the inflammation site in an animal model for fungal airway allergy [32]. Neutrophils could also act as antigen-presenting cells to promote IL-17 production by $\mathrm{CD} 4$ and $\mathrm{CD} 8^{+} \mathrm{T}$ cells [33-35].

Finally, we observed that the percentage of $\mathrm{CD} 4^{+} \mathrm{IL}-17^{+}$ $\mathrm{T}$ cells in peripheral blood of patients was associated with the severity of asthma, confirming observations described by other groups $[6-9,21,36]$. We also observed an increase of $\mathrm{CD} 4^{+} \mathrm{IL}-17^{+} \mathrm{T}$ cells in acute asthma, reinforcing the importance of IL-17A in the immunopathology of asthma. Furthermore, in contrast to neutrophils, the production of IL-17 by $\mathrm{CD} 4^{+} \mathrm{T}$ cells was independent of the type of allergen. Importantly, Pelletier, $\mathrm{M}$ et al., described a chemokine-dependent reciprocal cross-talk between human neutrophils and Th17 cells. They described that activated neutrophils induce chemotaxis of Th17 cells by release of CCL2 and CCL20 chemokines. At the same time, CXCL8 is produced by Th17 to chemoattract neutrophils. They also found that $\mathrm{CD} 15^{+}$neutrophils and $\mathrm{ROR}^{+} \mathrm{t}^{+}$cells colocalize in gut tissue from patients with Crohn disease and synovial fluid from rheumatoid arthritis patients [37]. It is likely that the recruitment of neutrophils and Th17 in response to allergen is mediated by the chemokine cross-talk described above.

As it is now known, Th17 response is important for host defense against extracellular bacteria and fungi by indirectly inducing and activating neutrophils through production of IL-17A and IL-17 F. In this context, our study found higher percentage of $\mathrm{IL}-17^{+}$neutrophils in 
asthma patients who are allergic to fungi. This suggests that this cell subpopulation might be activated by fungal allergens to release IL-17.

\section{Conclusion}

We identified a subpopulation of CD177 ${ }^{+} \mathrm{IL}-17 \mathrm{~A}^{+}$neutrophils in peripheral blood of asthmatic patients and healthy controls. Even though we were able to appreciate differences between asthmatic groups, due to the number of analyzed patients, it is not possible to define the relation between this subpopulation and severity of asthma.

\section{Abbreviations}

FEV1: Forced expiratory volume in 1 second; FITC: Fluorescein isothiocyanate; PMA: Phorbol myristate acetate; FACS: Flow cytometry (fluorescenceactivated cell sorting); SEM: Standard error of the mean; FSC: Forward scatter; SSC: Side scatter; HWB: Heparinized whole blood; PBMC: Peripheral blood mononuclear cell; IL: Interleukin; $T_{H}$ : T helper.

\section{Competing interest}

The authors declared no conflict of interest.

\section{Authors' contributions}

CRV and VON designed the experiments; LGB selected the patients; CRV did the experiments; CRV, ECC and VON analyzed the data and wrote the manuscript. All authors read and approve the final manuscript.

\section{Acknowledgments}

The authors are grateful for the support of CONACyT (grant 24312 to VON and scholarship 20700 to CRV) and CINVESTAV-IPN, Zacatenco. We thank María de Los Angeles Hernandez-Cueto for assistance with statistical analysis, and Ismael Carrillo-Martín on the discussion of manuscript.

\section{Author details}

Molecular Biomedicine Department, Centro de Investigación y de Estudios Avanzados (CINVESTAV)-IPN, Av. IPN No. 2508, Colonia San Pedro Zacatenco, México, DF CP. 07360, México. ²Allergy Department, Hospital General Dr. Fernando Quiroz Gutiérrez, ISSSTE, Calle Felipe Angeles y Canario. Colonia Bellavista, Mexico, DF CP 01140, Mexico. ${ }^{3}$ Allergy Department, Centro Médico Nacional 20 de Noviembre ISSSTE, Felix Cuevas 540, Colonia del Valle, Mexico, DF CP 03229, Mexico.

Received: 27 February 2013 Accepted: 30 June 2013

Published: 3 July 2013

\section{References}

1. Hammad $H$, Lambrecht BN: The airway epithelium in asthma. Nat Med 2012, 18:684-692

2. Thumerelle C, Deschildre A, Bouquillon C, et al: Role of viruses and atypical bacteria in exacerbations of asthma in hospitalized children: $\mathrm{A}$ prospective study in the Nord-Pas de Calais region (France). Pediatr Pulmonol 2003, 35:75-82.

3. Murray CS: Study of modifiable risk factors for asthma exacerbations: virus infection and allergen exposure increase the risk of asthma hospital admissions in children. Thorax 2006, 61:376-382.

4. Hamid Q, Tulic M: Immunobiology of asthma. Ann Rev Physio/ 2009 71:489-507.

5. Woodruff PG, Modrek B, Choy DF, et al: T-helper type 2-driven inflammation defines major subphenotypes of asthma. Am J Resp Crit Care Med 2009, 180:388-395.

6. Pène J, Chevalier $S$, Preisser $L$, et al: Chronically inflamed human tissues are infiltrated by highly differentiated Th17 lymphocytes. J Immunol 2008, 180:7423-7430.

7. Al-Ramli W, Préfontaine D, Chouiali F, et al: TH17-associated cytokines (IL-17A and IL-17F) in severe asthma. J Allergy Clin Immunol 2009, 123:1185-1187.
8. McKinley L, Alcorn JF, Peterson A, et al: TH17 cells mediate steroid-resistant airway inflammation and airway hyperresponsiveness in mice. $\mathrm{J}$ Immunol 2008, 181:4089-4097.

9. Green $\mathrm{RH}$, Brightling $\mathrm{CE}$, Woltmann $\mathrm{G}$, et al: Analysis of induced sputum in adults with asthma: identification of subgroup with isolated sputum neutrophilia and poor response to inhaled corticosteroids. Thorax 2002, 57:875-879.

10. Jatakanon A, Uasuf C, Maziak W, et al: Neutrophilic inflammation in severe persistent asthma. Am J Respir Crit Care Med 1999, 160:1532-1539.

11. Hastie AT, Moore WC, Meyers DA, et al: Analyses of asthma severity phenotypes and inflammatory proteins in subjects stratified by sputum granulocytes. J Allergy Clin Immunol 2010, 125:1028-1036.

12. Lommatzsch $M$, Julius $P$, Kuepper $M$, et al: The course of allergen-induced leukocyte infiltration in human and experimental asthma. J Allergy Clin Immunol 2006, 118:91-97.

13. Ferretti $\mathrm{S}$, Bonneau $\mathrm{O}$, Dubois $\mathrm{GR}$, et al: IL-17, produced by lymphocytes and neutrophils, is necessary for lipopolysaccharide-induced airway neutrophilia: IL-15 as a possible trigger. J Immunol 2003, 170:2106-2112.

14. Fei $M$, Bhatia $S$, Oriss TB, et al: TNF-a from inflammatory dendritic cells (DCs) regulates lung IL-17A/IL-5 levels and neutrophilia versus eosinophilia during persistent fungal infection. PNAS 2011, 108:5360-5365.

15. Fahy J, Kim K, Boushey $\mathrm{H}$ : Prominent neutrophilic inflammation in sputum from subjects with asthma exacerbation. J Allergy Clin Immunol 1995, 95:843-852.

16. Foley SC, Hamid Q: Images in allergy and immunology: neutrophils in asthma. J Allergy Clin Immunol 2007, 119:1282-1286.

17. Qiu Y, Zhu J, Bandi V, et al: Bronchial mucosal inflammation and upregulation of CXC chemoattractants and receptors in severe exacerbations of asthma. Thorax 2007, 62:475-482.

18. Asman B, Strand V, Bylin G, et al: Peripheral neutrophils after allergic asthmatic reactions. Int J Clin Lab Res 1997, 27:185-188.

19. Sun YC, Zhou QT, Yao WZ: Sputum interleukin-17 is increased and associated with airway neutrophilia in patients with severe asthma. Chin Med J (Engl) 2005, 118:953-956.

20. Song C, Luo L, Lei Z, et al: IL-17-producing alveolar macrophages mediate allergic lung inflammation related to asthma. J Immunol 2008, 181:6117-6124.

21. Zhao Y, Yang J, Gao YD, et al: Th17 Immunity in patients with allergic asthma. Int Arch Allergy Immunol 2010, 151:297-307.

22. Korn T, Bettelli E, Oukka M, et al: IL-17 and Th17 Cells. Ann Rev Immunol 2009, 27:485-517.

23. Li L, Huang L, Vergis AL, et al: IL-17 produced by neutrophils regulates IFN- $\gamma$-mediated neutrophil migration in mouse kidney ischemia-reperfusion injury. J Clin Invest 2010, 120:331-342.

24. Bateman $E$, Hurd S, Barnes P, et al: Global strategy for asthma management and prevention: GINA executive summary. Eur Respir J 2008, 31:143-178

25. Pinto LA, Depner $M$, Klopp N, et al: MMP-9 gene variants increase the risk for non-atopic asthma in children. Respir Res 2010, 11:23.

26. Taylor M, Zweiman B, Moskovitz A, et al: Platelet-activating factor- and leukotriene B4-induced release of lactoferrin from blood neutrophils of atopic and nonatopic individuals. J Allergy Clin Immunol 1990, 86:740-748.

27. Loukides S, Bouros D, Papatheodorou G, et al: The relationships among hydrogen peroxide in expired breath condensate, airway inflammation, and asthma severity. Chest 2002, 121:338-346.

28. Gibson PG, Simpson JL, Saltos N: Heterogeneity of airway inflammation in persistent asthma: evidence of neutrophilic inflammation and increased sputum interleukin-8. Chest 2001, 119:1329-1336.

29. Tan $Z$, Jiang $R$, Wang $X$, et al: RORgt + IL-17+ neutrophils play a critical role in hepatic ischemia-reperfusion injury. J Mol Cell Biol 2013, 5:143-146

30. Inoue $\mathrm{K}$, Takano $\mathrm{H}$, Koike $\mathrm{E}$, et al: Candida soluble cell wall beta-glucan facilitates ovalbumin-induced allergic airway inflammation in mice: Possible role of antigen-presenting cells. Respir Res 2009, 10:68.

31. Werner IL, Gessner MA, Lilly LM et al: Neutrophils produce interleukin 17A (IL-17A) in a dectin-1- and IL-23-dependent manner during invasive fungal infection. Infect Immun 2011, 79:3966-3977.

32. Park S, Wiekowski M, Lira S, Mehrad B: Neutrophils regulate airway responses in a model of fungal allergic airways disease. J Immunol 2006 176:2538-2545. 
33. Abi Abdallah DS, Egan $C E$, Butcher $B A$, et al: Mouse neutrophils are professional antigen-presenting cells programmed to instruct Th1 and Th17 T-cell differentiation. Int Immunol 2011, 23:317-326.

34. Beauvillain C, Delneste $Y$, Scotet $M$, et al: Neutrophils efficiently cross-prime naive T cells in vivo. Blood 2007, 110:2965-2973.

35. Yang CW, Strong BSI, Miller MJ, et al: Neutrophils influence the level of antigen presentation during the immune response to protein antigens in adjuvants. J Immunol 2010, 185:2927-2934.

36. Kudo M, Melton AC, Chen C, et al: IL-17A produced by a $\mathrm{B}$ cells drives airway hyper-responsiveness in mice and enhances mouse and human airway smooth muscle contraction. Nat Med 2012, 18:547-554.

37. Pelletier M, Maggi L, Micheletti A, et al: Evidence for a cross-talk between human neutrophils and Th17 cells. Blood 2010, 115:335-343.

doi:10.1186/1710-1492-9-23

Cite this article as: Ramirez-Velazquez et al:: IL-17-producing peripheral blood $\mathrm{CD} 177^{+}$neutrophils increase in allergic asthmatic subjects. Allergy, Asthma \& Clinical Immunology 2013 9:23.

\section{Submit your next manuscript to BioMed Central and take full advantage of:}

- Convenient online submission

- Thorough peer review

- No space constraints or color figure charges

- Immediate publication on acceptance

- Inclusion in PubMed, CAS, Scopus and Google Scholar

- Research which is freely available for redistribution 